Rev. Inst. Flor. v. 26 n. 1 p. 55-69 2014

http://dx.doi.org/10.4322/rif.2014.004

ISSN impresso 0103-2674/on-line 2178-5031

\title{
EDUCAÇÃO AMBIENTAL E A CONSERVAÇÃO DA ONÇA PARDA: POTENCIAIS DAS UNIDADES DE CONSERVAÇÃO DO NORDESTE PAULISTA ${ }^{1}$
}

\author{
ENVIRONMENTAL EDUCATION AND PUMA CONSERVATION: \\ POTENTIALS OF THE PROTECTED AREAS OF NORTHEASTERN SÃO PAULO STATE (BRAZIL)
}

\author{
Mayla Willk VALENTI ${ }^{2,4}$; Sara Monise de OLIVEIRA ${ }^{2}$; \\ Renata Alonso MIOTTO ${ }^{3}$; Haydée Torres de OLIVEIRA ${ }^{2}$
}

\begin{abstract}
RESUMO - No nordeste do Estado de São Paulo as unidades de conservação abrigam importante parcela da biodiversidade brasileira. Espécies predadoras de topo de cadeia, como a onça parda (Puma concolor), ainda estão presentes nessa região e dependem dessas unidades para sobreviverem. Nesse contexto, a educação ambiental pode contribuir com a conservação das espécies, embora existam desafios a serem superados. O objetivo deste trabalho foi identificar potencialidades e limites da educação ambiental para a conservação da biodiversidade nas unidades de conservação do nordeste paulista, tendo como tema a conservação de predadores, em especial a onça parda. A área de estudo foi definida com base na população dessa espécie na região. Realizamos levantamento das unidades de conservação na área de estudo e consulta para identificar aquelas com programas de educação ambiental ativos. Visitamos sete áreas protegidas, sendo que em cada uma realizamos entrevista estruturada com pessoas envolvidas em ações de educação ambiental e/ou gestores das unidades, totalizando sete entrevistas. Os dados indicaram que essas unidades estão em contextos relevantes para a realização de ações educativas voltadas à conservação de predadores. Contudo, as/os entrevistadas/os relataram dificuldades em se aproximar da população do entorno fora do ambiente escolar, especialmente o público adulto. Apesar disso, identificamos uma preocupação em envolver a comunidade do entorno, percebida nos próprios objetivos das atividades realizadas pelas unidades de conservação. A partir dos resultados obtidos, consideramos que, embora o tema dos predadores não seja especificamente trabalhado, existe um potencial grande para atuação nesse sentido. Ainda, destacamos que as unidades de conservação são espaços privilegiados para a integração dos conhecimentos científicos e educação ambiental.
\end{abstract}

Palavras-chave: áreas protegidas; predadores de topo de cadeia; Puma concolor.

\begin{abstract}
In northeastearn São Paulo state (Brazil), the protected areas shelter important portion of Brazilian biodiversity. Top-chain predators, such as puma (Puma concolor) still remain in this region and need these areas to survive. In this context, environmental education can contribute to the conservation of these species, although there are challenges to overcome. The aim of this paper was to identify potentialities and limits of environmental education to biodiversity conservation in the protected areas of northeastearn São Paulo state from the theme of predator conservation, particularly pumas. The studied area was defined based on the distribution of puma's population in the region. A research of protected areas and a consultation to identify the ones with ongoing environmental education programs were perfomed. Seven protected areas were visited where we conducted an structured interview with people involved in environmental education actions and/or with the managers of the areas, totalizing seven interviews. Data indicated that these areas are in relevant contexts for performing educational actions for predator conservation.
\end{abstract}

\footnotetext{
${ }^{1}$ Recebido para análise em 02.10.13. Aceito para publicação em 02.07.14.

¿Universidade Federal de São Carlos, Campus São Carlos, Laboratório de Educação Ambiental, Departamento de Ciências Ambientais, Rodovia Washington Luis, km 235, 13565-905 São Carlos, SP, Brasil.

${ }^{3}$ Universidade de São Paulo, Departamento de Ciências Florestais, Campus Luiz de Queiroz, Avenida Pádua Dias, 11, 13418-900 Piracicaba, SP, Brasil.

${ }^{4}$ Autor para correspondência: Mayla Willk Valenti - maylabio@hotmail.com
} 
However, interviewers reported difficulties in approaching to the surrounding community in non-scholar contexts, specially the adult audience. Nevertheless, we identified concerns about involving the surrounding community, perceived by the aims of the activities performed in the protected areas. From our results, we consider that, although predator conservation was not cited as a theme addressed in the education activities, there is a great potential to act in that sense. Besides, we emphasize that the protected areas are privileged spaces to integrate scientific knowledge and environmental education.

Keywords: protected areas; Puma concolor; top-chain predators.

\section{INTRODUÇÃO}

Na região nordeste do Estado de São Paulo as unidades de conservação abrigam importante parcela da biodiversidade associada à floresta estacional semidecídua e ao cerrado (Batalha e Mantovani, 2000; Talamoni et al., 2000; Rodrigues e Bononi, 2008). Espécies de grandes carnívoros, como a onça parda (Puma concolor), estão presentes nessa região e no interior dessas unidades. Aparentemente, as unidades de conservação atuam como áreas fonte na paisagem, i.e., áreas onde animais residentes se reproduzem e criam seus filhotes (Miotto et al., 2012). Elas também têm grande importância no processo de dispersão dos juvenis, no estabelecimento de indivíduos e, consequentemente, na manutenção da diversidade genética, fundamental para a viabilidade das populações. Contudo, por ser um predador de topo de cadeia alimentar generalista e possuir grande área de vida, essa espécie depende de todo o mosaico da paisagem para manter sua viabilidade ao longo prazo, sendo necessárias ações de conservação em âmbito regional.

Nesse sentido, a conservação dessa espécie no interior do Estado de São Paulo é desafiadora diante da paisagem fragmentada e do crescente desenvolvimento da região. Os índices de cobertura vegetal são baixos, e os de fragmentação, altos. Além disso, a maioria das unidades de conservação possui dimensões pequenas e se encontra com pouca conectividade na paisagem (Rodrigues $\mathrm{e}$ Bononi, 2008). Nas últimas décadas, o intenso crescimento dos centros urbanos e da malha rodoviária da região nordeste do Estado tem gerado pressões sobre a população de onças pardas residente, especialmente pela perda de habitats, atropelamentos e conflitos com seres humanos e suas criações domésticas (Miotto et al., 2011; 2012).
De acordo com Joly et al. (2010), poucos projetos de conservação da biodiversidade no Estado de São Paulo focam as dimensões humanas da biodiversidade, indicando a priorização desta temática no fomento à pesquisa científica para o decênio 2011-2020. Diante disso, identificamos a importância das ações de educação ambiental voltadas ao público adulto para promover a conservação da espécie. Esse mesmo aspecto foi enfatizado por Pádua (2010) para a região do Pontal do Paranapanema.

A educação ambiental é um processo educativo que pode contribuir com a diminuição das ameaças à biodiversidade (Rodrigues, 2007). Em nossas práticas educativas e de pesquisa adotamos uma perspectiva crítica de educação ambiental, que tem como um de seus princípios a concepção sistêmica do meio ambiente, considerando suas múltiplas relações (Guimarães, 2001). Por meio do estabelecimento de processos coletivos, a educação ambiental nessa abordagem possibilita a formação de valores e atitudes sensíveis à diversidade, à complexidade e à solidariedade diante dos outros seres humanos e da natureza (Carvalho, 1998). Portanto, a educação ambiental é um instrumento fundamental para a conservação da diversidade biológica e cultural (Brasil, 2002) e pode contribuir com a solução de conflitos reais que atingem as unidades de conservação e seu entorno.

As unidades de conservação são espaços privilegiados para se discutir o tema da biodiversidade (Silva, 2004; Brasil, 2005; 2010; Valenti, 2010). Nesses locais, é possível a realização de diferentes ações educativas (Marin et al., 2003; Mendonça, 2007; Menghini et al., 2007) e ainda a participação popular na gestão ambiental do território onde a unidade está inserida (Quintas, 2002; Loureiro, 2004; Sammarco, 2009; Pádua, 2010). 
VALENTI, M.W. et al. Educação ambiental em unidades de conservação do nordeste paulista

Por serem áreas em que se aglutinam inúmeras e complexas questões ambientais, sociais, políticas, econômicas e culturais, as unidades de conservação apresentam grande potencial para o desenvolvimento de ações de educação ambiental com uma abordagem crítica (Valenti, 2010). Nesse sentido, as ações educativas contribuem para a conservação da biodiversidade porque propiciam novas relações com a natureza e com a sociedade e a ação diante dos problemas ambientais (Carvalho, 2001; Guimarães, 2004; Hamú et al., 2004; Mendonça, 2005; Oliveira, 2008).

Algumas das unidades da região nordeste do estado possuem uma estrutura física mínima e têm ou já tiveram um programa ativo de educação ambiental. Contudo, há poucos registros na literatura sobre a educação ambiental existente ou potencial nas unidades de conservação do interior paulista (Santos et al., 2000; Toledo e Pelicioni, 2006; Menarin, 2009; Santos et al., 2010; Valenti, 2010; Oliveira et al., 2012). Mesmo naquelas em que há relatos de ações educativas, alguns desafios para a inclusão da comunidade do entorno nas atividades da unidade são citados (Santos et al., 2000; Menarin, 2009). Nesse contexto, consideramos importante conhecer o trabalho de educação ambiental realizado pelas unidades de conservação do nordeste paulista e identificar suas potencialidades para contribuir com ações de conservação da biodiversidade local, tomando como espécie bandeira a onça parda.

Portanto, nosso objetivo geral, neste trabalho, foi identificar potencialidades e limites da educação ambiental para a conservação da biodiversidade nas unidades de conservação do nordeste paulista, tendo como tema a conservação de grandes carnívoros, em especial a onça parda, conforme os pontos de ocorrência da espécie na região. Para tanto, procuramos desenvolver os seguintes objetivos específicos:

- listar as unidades de conservação existentes na área de ocorrência da onça parda no nordeste paulista e identificar quais possuem programas ativos de educação ambiental;

- caracterizar as ações de educação ambiental das unidades de conservação listadas que possuem programas ativos;
- identificar quais estratégias educativas podem facilitar ações de educação ambiental com o entorno das unidades de conservação em regiões urbanizadas, e

- identificar as potencialidades das unidades de conservação para atuar com educação ambiental voltada à conservação da biodiversidade, em especial na conservação de grandes carnívoros, junto ao público adulto.

\section{PROCEDIMENTOS METODOLÓGICOS}

Definimos a área de estudo desse trabalho com base na pesquisa sobre a população de onças pardas conduzida por Miotto et al. (2011; 2012). Optamos por esta área de estudo por ela nos permitir integrar a pesquisa em conservação da biodiversidade com a pesquisa em educação ambiental, buscando compreender aspectos humanos necessários para a conservação da biodiversidade no Estado de São Paulo. A área possui aproximadamente $35.000 \mathrm{~km}^{2}$ e abrange 130 municípios do nordeste paulista (Figura 1), que juntos somam uma população de mais de quatro milhões de habitantes (Instituto Brasileiro de Geografia e Estatística - IBGE, 2009), distribuídos principalmente nas zonas urbanas. O principal uso agrícola nesta região é a produção de cana-de-açúcar, seguido da silvicultura, citricultura e pecuária. A vegetação nativa é composta por remanescentes de floresta estacional semidecídua e cerrado, localizados em pequenos fragmentos, sendo alguns deles protegidos em unidades de conservação (Rodrigues e Bononi, 2008).

A coleta e análise dos dados seguiram as bases da pesquisa qualitativa (Denzin e Lincoln, 2006). Sendo assim, o objetivo não foi buscar relações de causa e efeito ou quantificar a expressão de um determinado fenômeno, mas compreender um contexto sociocultural, levantando variações na expressão desse fenômeno inserido nesse contexto. De acordo com Denzin e Lincoln (2006), a pesquisa qualitativa é um campo amplo, que agrega diferentes práticas teórico-metodológicas. Neste trabalho, tivemos como horizonte a proposta de Gomez et al. (2006), denominada metodologia comunicativa crítica. 

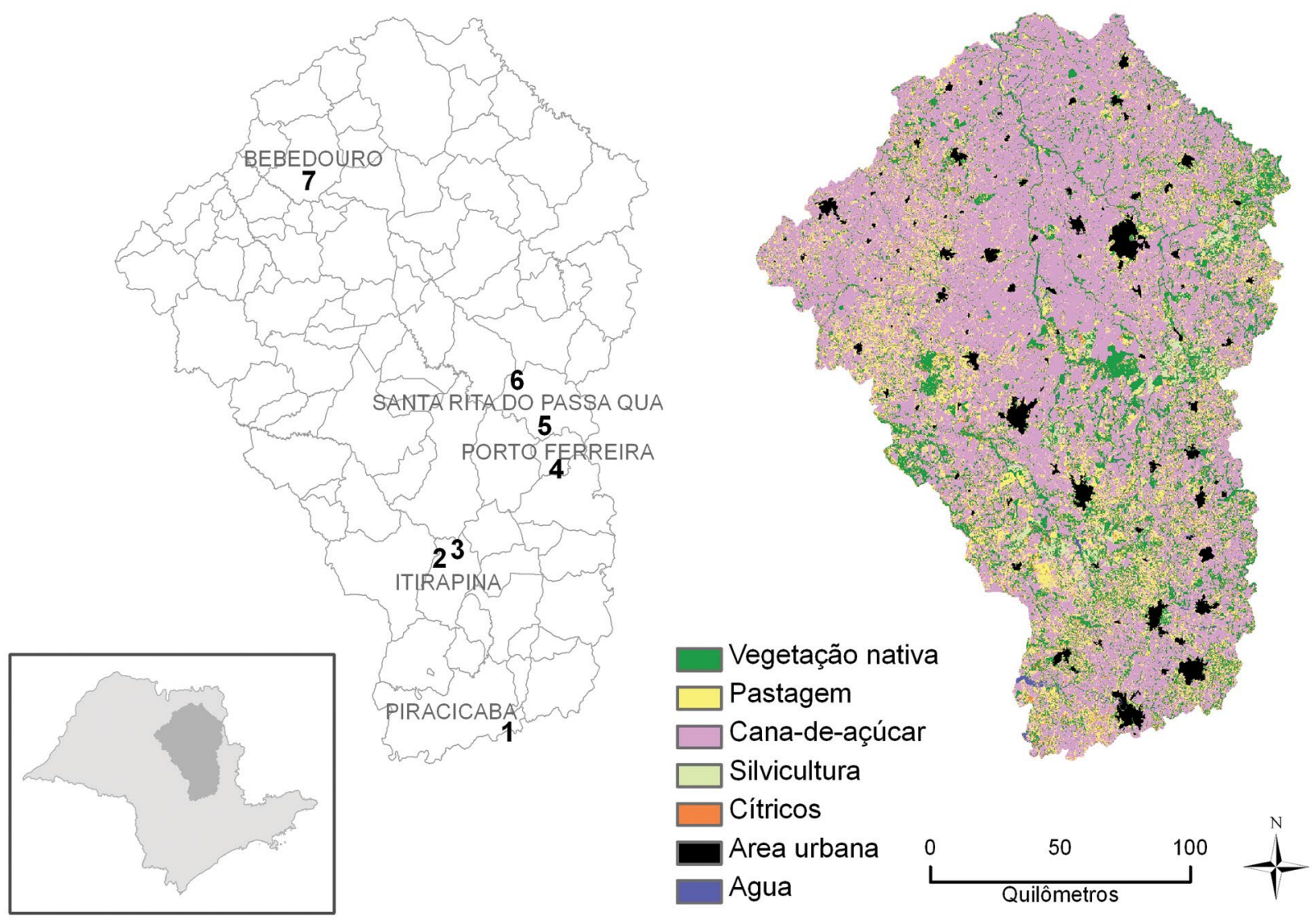

Figura 1. Classes de uso e cobertura do solo, municípios e unidades de conservação visitadas na região nordeste do estado de São Paulo. (1) Estação Experimental de Tupi (2) Estação Ecológica de Itirapina (3) Estação Experimental de Itirapina (4) Parque Estadual de Porto Ferreira (5) Estação Experimental de Santa Rita (6) Parque Estadual do Vassununga (7) Floresta Estadual de Bebedouro.

Figure 1. Classification of uses and soil cover, municipalities and protected areas visited in northeastern São Paulo state. (1) Experimental Station of Tupi (2) Ecological Station of Itirapina (3) Experimental Station of Itirapina (4) State Park of Porto Ferreira (5) Experimental Station of Santa Rita (6) State Park Vassununga (7) State Forest of Bebedouro. 
A metodologia comunicativa crítica privilegia o papel da intersubjetividade e da argumentação na construção do conhecimento, buscando a transformação da realidade estudada no sentido de uma sociedade mais igualitária. Desse modo, durante o processo de construção dos dados, procuramos estabelecer uma relação de diálogo com as pessoas participantes do estudo, considerando a contribuição de cada uma para a melhor compreensão da realidade estudada. Contudo, é importante esclarecer que no âmbito deste estudo, houve limitações para a aplicação em profundidade da metodologia crítica, dada à sua própria complexidade e restrições de tempo para a realização deste diagnóstico. Apesar disso, procuramos seguir alguns de seus princípios. Uma das ações da prática de pesquisa nesse sentido foi apresentar os dados e as análises realizadas aos sujeitos da pesquisa, buscando a validação da interpretação dos resultados e uma interlocução na produção do conhecimento.

Realizamos o levantamento das unidades de conservação da área de ocorrência das onças pardas utilizando a base de dados do programa Biota/Fapesp (Rodrigues e Bononi, 2008) e os sites da Fundação Florestal (http://www.fflorestal.sp.gov.br) e do Instituto Florestal (http://www.iflorestal.sp.gov.br), órgãos responsáveis pelo gerenciamento das unidades de conservação no Estado de São Paulo. Em agosto de 2011, listamos as unidades de interesse e enviamos a lista para as coordenações de educação ambiental da Fundação Florestal e do Instituto Florestal para que indicassem quais unidades possuíam infraestrutura mínima de uso público e programas de educação ambiental ativos.

Em setembro e outubro de 2011, visitamos sete unidades indicadas para conhecer e caracterizar as ações de educação ambiental desenvolvidas e identificar as potencialidades para a realização de atividades junto à comunidade do entorno rural e urbano, especialmente ao público adulto. As visitas foram feitas com o acompanhamento das/os gestoras/es das unidades e/ou pessoas responsáveis por ações de educação ambiental. Durante a visita, realizamos uma entrevista estruturada em cada unidade, preenchendo um questionário amplo sobre o programa de educação ambiental da unidade. Também foi realizado registro fotográfico das estruturas educativas mencionadas na entrevista. Portanto, realizamos um total de sete entrevistas.
O material de registro das entrevistas foi transcrito e organizado em arquivos separados por unidade de conservação. Estes foram enviados às/aos entrevistadas/os para que pudessem conferir as informações apresentadas e sugerir as modificações que julgassem necessárias. Após realizar as correções, reunimos o material para a análise dos resultados e elaboração do artigo, que também teve sua primeira versão enviada para a apreciação das/os entrevistadas/os.

A análise das entrevistas foi feita com base na identificação de aspectos-chave para responder aos objetivos do trabalho. Assim, do amplo conjunto de questões formuladas para caracterização das ações de educação ambiental nesse contexto, extraímos apenas os resultados de questões relacionadas às potencialidades para ações de educação ambiental direcionadas à conservação da onça parda na região, tema do presente artigo. Para tanto, selecionamos dois critérios de análise principais: ações voltadas às comunidades do entorno emum contexto urbanizado e o desenvolvimento de atividades voltadas ao público adulto. Sendo assim, analisamos as seguintes questões: características do entorno, objetivos das ações educativas, público, atividades, temas e ações direcionadas à conservação da onça parda e às suas ameaças.

\section{RESULTADOS E DISCUSSÃO}

$\mathrm{Na}$ área de estudo foram levantadas 20 unidades de conservação, sendo sete de proteção integral (dois Parques Estaduais e cinco Estações Ecológicas) e 13 de uso sustentável (sete Estações Experimentais, quatro Florestas Estaduais e duas Áreas de Proteção Ambiental; Quadro 1). A categoria de Estação Experimental não está prevista no SNUC (Brasil, 2000), mas se assemelha às Florestas Estaduais e, por isso, foi considerada de uso sustentável. Essa diversidade de categorias na região pode ser interessante, pois o conjunto reúne unidades mais restritivas e outras que permitem maior acesso ao público. As unidades da categoria Estação Ecológica, por exemplo, são as mais restritivas, sendo permitidas apenas atividades educativas e de pesquisa. Já as Estações Experimentais, as Florestas Estaduais e as Áreas de Proteção Ambiental permitem a visitação pública, seguindo condições estabelecidas no plano de manejo da unidade (Brasil, 2000). 
VALENTI, M.W. et al. Educação ambiental em unidades de conservação do nordeste paulista

Quadro 1. Características das unidades de conservação do nordeste paulista (US = uso sustentável, PI = proteção integral, IF = Instituto Florestal, FF = Fundação Florestal; em negrito estão as unidades visitadas neste estudo.

Table 1. Characteristics of protected areas of northeastearn São Paulo state, Brazil (US = sustainable use, PI $=$ strict nature reserve, IF = Forestry Institute, FF = Forestry Foundation; names in bold are the areas visited in this study).

\begin{tabular}{|c|c|c|c|c|c|}
\hline Unidade de Conservação & Municípios & $\begin{array}{l}\text { Área } \\
\text { (ha) }\end{array}$ & Categoria & Órgão & $\begin{array}{l}\text { Possui programa de } \\
\text { educação ambiental } \\
\text { ativo? }\end{array}$ \\
\hline Floresta Estadual de Batatais & Batatais & 1.353 & US & IF & Não (esporádicas) \\
\hline Floresta Estadual de Cajuru & $\begin{array}{l}\text { Cajuru e } \\
\text { Altinópolis }\end{array}$ & 1.909 & US & IF & Não \\
\hline Floresta Estadual de Bebedouro & Bebedouro & 99 & US & IF & Sim \\
\hline Parque Estadual Porto Ferreira & Porto Ferreira & 611 & PI & FF & Sim \\
\hline Parque Estadual Vassununga & $\begin{array}{l}\text { Santa Rita do } \\
\text { Passa Quatro }\end{array}$ & 2.071 & PI & FF & Sim \\
\hline Estação Experimental de Santa Rita & $\begin{array}{l}\text { Santa Rita do } \\
\text { Passa Quatro }\end{array}$ & 96 & US & IF & Sim \\
\hline Estação Ecológica de Jataí & Luiz Antônio & 4.532 & PI & FF & Não (esporádicas) \\
\hline Estação Experimental de Luiz Antônio & Luiz Antônio & 1.725 & US & IF & Não (esporádicas) \\
\hline Estação Ecológica de Ribeirão Preto & Ribeirão Preto & 154 & PI & $\mathrm{FF}$ & Não (esporádicas) \\
\hline Estação Experimental de Araraquara & Araraquara & 143 & US & IF & Não (esporádicas) \\
\hline Estação Ecológica de São Carlos & São Carlos & 75 & PI & $\mathrm{FF}$ & Não (esporádicas) \\
\hline Estação Ecológica de Itirapina & $\begin{array}{l}\text { Brotas e } \\
\text { Itirapina }\end{array}$ & 2.300 & PI & IF & Sim \\
\hline Estação Experimental de Itirapina & Itirapina & 3.212 & US & IF & Sim \\
\hline $\begin{array}{l}\text { Área de Proteção Ambiental } \\
\text { de Corumbataí }\end{array}$ & $\begin{array}{l}\text { Analândia, } \\
\text { Barra Bonita, } \\
\text { Brotas, } \\
\text { Charqueada, } \\
\text { Corumbataí, } \\
\text { Dois Córregos, } \\
\text { Ipeuna, } \\
\text { Itirapina, } \\
\text { Mineiros do } \\
\text { Tietê, Rio } \\
\text { Claro, Santa } \\
\text { Maria da Serra, } \\
\text { São Carlos, São } \\
\text { Manoel, São } \\
\text { Pedro, Torrinha }\end{array}$ & 272.692 & US & $\mathrm{FF}$ & Não (parcerias) \\
\hline
\end{tabular}


VALENTI, M.W. et al. Educação ambiental em unidades de conservação do nordeste paulista

continuação - Quadro 1

continuation - Table 1

\begin{tabular}{|c|c|c|c|c|c|}
\hline Unidade de Conservação & Municípios & $\begin{array}{l}\text { Área } \\
\text { (ha) }\end{array}$ & Categoria & Órgão & $\begin{array}{l}\text { Possui programa de } \\
\text { educação ambiental } \\
\text { ativo? }\end{array}$ \\
\hline Estação Ecológica de Ibicatu & Piracicaba & 76 & PI & $\mathrm{FF}$ & Não \\
\hline Estação Experimental de Tupi & Piracicaba & 198 & US & IF & Sim \\
\hline $\begin{array}{l}\text { Área de Proteção Ambiental } \\
\text { de Piracicaba }\end{array}$ & $\begin{array}{l}\text { Analândia, } \\
\text { Charqueada, } \\
\text { Corumbataí, } \\
\text { Ipeuna, } \\
\text { Itirapina, Rio } \\
\text { Claro }\end{array}$ & 107.000 & US & $\mathrm{FF}$ & Não (parcerias) \\
\hline $\begin{array}{l}\text { Floresta Estadual } \\
\text { Edmundo Navarro de Andrade }\end{array}$ & Rio Claro & 2.230 & PI & $\mathrm{FF}$ & Sim \\
\hline $\begin{array}{l}\text { Estação Experimental } \\
\text { de Bento Quirino }\end{array}$ & São Simão & 416 & US & IF & Não (esporádicas) \\
\hline Estação Experimental de São Simão & São Simão & 927 & US & IF & Não \\
\hline
\end{tabular}

Fontes: consulta às coordenações de educação ambiental do Instituto Florestal (SP) e da Fundação Florestal (SP).

Entre as 20 unidades listadas, apenas oito possuem programas ativos de educação ambiental, sete realizam atividades esporádicas ou eventos $\mathrm{e}$ cinco não realizam atividades de educação ambiental. Apesar de a categoria da unidade ordenar o tipo de uso público permitido, a existência do programa de educação ambiental não está relacionada à categoria, já que unidades da mesma categoria podem ou não apresentar programas de educação ambiental (Tabela 1). Das oito unidades com programas ativos, sete foram visitadas e incluídas na pesquisa, totalizando sete entrevistas estruturadas realizadas. A Estação Experimental e a Estação Ecológica de Itirapina foram consideradas em conjunto, respondendo a uma entrevista única, pois possuem plano de manejo integrado. Entre as unidades visitadas, apenas a Estação Experimental e a Estação Ecológica de Itirapina e o Parque Estadual de Porto Ferreira possuem planos de manejo concluídos, os quais descriminam a área de uso público e contemplam programas de educação ambiental (Tabanez et. al., 2003; Zanchetta et al., 2006).

Tabela1. Relação entre a categoria da unidade de conservação e a existência de programas de educação ambiental (EA) no nordeste paulista.

Table 1. Relation between the category of protected area and the presence of environmental education programs (EA) in northeastearn São Paulo state, Brazil.

\begin{tabular}{lcccc}
\hline Categoria & Programas ativos & Ações esporádicas & Sem ações & Total \\
\hline Estação Ecológica & 2 & 2 & 1 & 5 \\
Parque Estadual & 2 & 0 & 0 & 2 \\
Floresta Estadual & 2 & 1 & 1 & 4 \\
Estação Experimental & 3 & 3 & 1 & 7 \\
Área de Proteção Ambiental & 0 & 2 & 0 & 2 \\
\hline
\end{tabular}

Fontes: consulta às coordenações de educação ambiental do Instituto Florestal (SP) e da Fundação Florestal (SP). 
Os fatores que, em geral, limitam a existência dos programas de educação ambiental são a estrutura física e os recursos humanos e financeiros específicos para as ações de uso público (Carvalho et al., 1998; Silva, 2004). Assim, programas e políticas públicas que fortaleçam a estruturação da educação ambiental para a garantia das estruturas, equipe e recursos financeiros necessários à realização dos programas são de fundamental importância. No âmbito federal, a Estratégia Nacional de Comunicação e Educação Ambiental é uma iniciativa nesse sentido que visa fortalecer as ações de uso público e gestão participativa nas áreas naturais protegidas no âmbito do SNUC. No âmbito estadual, programas como "Trilhas de São Paulo" e "Criança Ecológica" foram importantes, pois proporcionaram a contratação de monitoras/es, melhoria da estrutura física e compra de equipamentos e material pedagógico para as ações de lazer e educação ambiental (Oliveira et al., 2012; Santos et al., 2010). Das unidades visitadas, quatro delas participavam do programa "Criança Ecológica", e uma do programa "Trilhas de São Paulo". As unidades que aderiram aos programas mencionaram a importância da estruturação da unidade para o fortalecimento das ações de educação ambiental, e as que não aderiram, indicaram a falta de recursos humanos e físicos como os principais problemas.

As unidades visitadas estão inseridas em contextos semelhantes e muito relevantes para o planejamento de ações de conservação da população de onças pardas na região. As sete unidades se encontram próximo às áreas urbanas, rodovias e propriedades rurais. Essa condição está diretamente relacionada às ameaças sofridas pela população de onças pardas: perda de habitats, atropelamentos e conflitos resultantes da interação com criação de animais domésticos em propriedades rurais (Miotto et al., 2011; 2012). Por outro lado, permite fácil acesso da população a esses espaços, o que potencializa as ações de uso público. Contudo, nas entrevistas realizadas, a interação com a comunidade do entorno foi apontada como um dos desafios para o desenvolvimento de ações educativas nesses espaços.
Nesse sentido, Bizerril et al. (2011) destacam a importância de envolver a comunidade local em ações de fato participativas que visem ao seu desenvolvimento social e não apenas informar as pessoas sobre os impactos ambientais sobre determinada espécie. Analisando os programas educativos de parques estaduais paulistas, Toledo e Pelicioni (2006) indicaram a importância do envolvimento das comunidades de entorno nos programas de educação ambiental e a responsabilidade da equipe das unidades em promover o fortalecimento deste vínculo com a comunidade. Para encontrar maneiras de ultrapassar esse desafio, é necessário compreender essas unidades sob uma perspectiva mais sistêmica, em sua relação com o contexto em que estão inseridas.

As unidades de conservação do nordeste paulista apresentam características comuns entre si no que se refere à interação com a comunidade, que as diferenciam das unidades de outras regiões do Estado de São Paulo ou do país. Na região do Vale do Ribeira e do Litoral Norte Paulista, por exemplo, há conflitos de terra e de uso dos recursos naturais nas unidades, mesmo naquelas de proteção integral. Apesar de estes fatos serem considerados problemas, não há como realizar a gestão desses espaços sem interagir com as populações que vivem dentro ou no entorno dessas unidades. Nesse sentido, a situação exige a realização de ações educativas com essas comunidades (Valenti, 2010). Já na região estudada, mesmo nas unidades consideradas de uso sustentável, não há moradores além de funcionários autorizados. Diferente do que ocorre em outras regiões, também não há presença de populações tradicionais, como quilombolas, caiçaras ou indígenas que dependam do extrativismo nessas áreas para sobreviver. Desse modo, existe maior dificuldade de acessar a população do entorno fora do ambiente escolar, especialmente o público adulto. Entretanto, é importante destacar que as unidades da região sofrem outros impactos ambientais oriundos da relação direta das pessoas com as áreas naturais, como por exemplo, a caça e a pesca ilegal (Tabanez et. al., 2003; Zanchetta et al., 2006). Portanto, é necessário desenvolver um programa educativo específico para as características dessa região. 
VALENTI, M.W. et al. Educação ambiental em unidades de conservação do nordeste paulista

A análise das informações obtidas nos questionários indicaram semelhanças não apenas no contexto em que as unidades estão inseridas, mas também nos objetivos para a educação ambiental e nas atividades desenvolvidas. Nesse sentido, foi possível elaborar uma síntese para ilustrar o cenário educativo das unidades de conservação do nordeste paulista (quadros 2 e 3). Na síntese apresentada no Quadro 2 é possível visualizar a preocupação das pessoas entrevistadas em envolver a comunidade do entorno ao mencionarem os objetivos do programa de educação ambiental. Essa preocupação também já tinha sido explicitada nos programas de educação ambiental dos planos de manejo de Porto Ferreira e Itirapina (Tabanez et al., 2003; Zanchetta et al., 2006), o que indica a importância dessa questão na região. Assim, destacamos essa temática como fundamental para pensar ações educativas para a conservação da onça parda em unidades de conservação do nordeste paulista.

Quadro 2. Objetivos das ações de educação ambiental realizadas em unidades de conservação do nordeste paulista.

Table 2. Aims of environmental education actions performed in protected areas of northeastearn São Paulo state (Brazil).

Objetivos das ações de educação ambiental

Integrar e envolver a comunidade visando à valorização e à conservação da unidade e da biodiversidade

Incentivar a participação da comunidade na gestão da unidade

Oferecer atividades de educação ambiental, interpretação da natureza e ecoturismo à comunidade

Capacitar docentes, educadoras/es/ e multiplicadoras/es, visando inclusive sua autonomia no desenvolvimento de ações educativas nas unidades e sua participação nas ações por elas realizadas

Promover a unidade como espaço educador na região

Informar os visitantes sobre as espécies nativas visando à recuperação de áreas degradadas

Sensibilizar e conscientizar a população sobre as questões ambientais e a dependência que os seres humanos possuem com relação à natureza

Desenvolver nos visitantes a observação e a percepção em relação aos ambientes da unidade, valorizando também os aspectos estéticos

Desenvolver a consciência crítica sobre a conservação ambiental e também sobre o contexto (histórico, social, político) em que a unidade está inserida

Elaborar instrumentos sistemáticos para avaliação do programa de uso público da unidade

Oferecer atividades atendendo a demandas institucionais da Secretaria do Meio Ambiente de São Paulo e da Fundação Florestal 
Para alcançar esses objetivos, as unidades atendem a diferentes públicos por meio de diferentes ações que envolvem vários tipos de atividades (Quadro 3). Essa diversidade amplia as possibilidades de relação das pessoas com a unidade. Todas as unidades possuem uma trilha interpretativa, o que é bastante positivo porque esta estratégia educativa proporciona o contato das pessoas com ambientes naturais, possibilitando o conhecimento de suas características e o desenvolvimento de vínculos afetivos com estes ecossistemas e lugares
(Benayas et al., 2000; Oliveira, 2009). Isso é de fundamental importância para a conservação da onça parda porque um dos grandes desafios da educação ambiental para a conservação da biodiversidade é justamente proporcionar o contato das populações, que atualmente vivem em sua grande maioria nas cidades, com o ambiente e fauna natural de sua região (Navarro-Perez e Tidball, 2012). Assim, a visita à trilha é uma maneira de aproximar as pessoas da região com o ambiente natural das onças pardas do território em que vivem.

Quadro 3. Tipos de atividades de educação ambiental desenvolvidas nas unidades de conservação do nordeste paulista (* envolvem principalmente público adulto).

Table 3. Types of environmental education activities performed in protected areas of northeastern São Paulo state, Brazil (*involve especially adult audience).

Tipos de atividades

Palestras de apresentação da unidade

Apresentação de slides, fotos e vídeos

Dinâmicas e jogos educativos

Estudos do meio e trilhas interpretativas

Visita a viveiro de produção de mudas

Visita a arboretos de espécies nativas

Visitas guiadas a centros de visitantes

Exposições de peças biológicas (animais taxidermizados, sementes, troncos, etc.)

Exposição de painéis informativos

Exposições artísticas (esculturas, fotos)*

Visitas espontâneas guiadas e autoguiadas (trilhas, centro de visitantes e espaços de lazer)*

Visitas de grupos universitários (guiadas ou independentes)*

Eventos em datas comemorativas

Clube que reúne crianças e jovens ao longo do ano

Cursos de férias

Formação de educadores*

Cursos e oficinas (produção de mudas, plantas medicinais, manejo de espécies peçonhentas)*

Atividades desenvolvidas fora da unidade (palestras e exposições)*

Participação em programa de rádio para divulgação da unidade*

Atendimento sob demanda (cursos e outras atividades sobre temas específicos)* 
VALENTI, M.W. et al. Educação ambiental em unidades de conservação do nordeste paulista

O público atendido pelas unidades inclui grupos escolares (estudantes e professoras/es) e outros grupos organizados, passando por setores profissionais, turistas e população local. Grande parte das unidades enfoca o trabalho com crianças, a partir do contato com as escolas. Essas ações geralmente são feitas em parceria com a secretaria ou departamento de educação do município. A principal ação desenvolvida com esse público é a visita guiada à unidade, que pode incluir diferentes tipos de atividade de acordo com a idade e com as condições climáticas do dia. Muitas vezes, também são oferecidos cursos de formação para as/os professoras/es e, eventualmente, são realizadas ações nas próprias escolas.

Um dos fatores que facilitam esse trabalho é o fácil acesso às/aos estudantes a partir de uma instituição organizada, que é a escola. Somando-se a isto, existe demanda das escolas por visitação a espaços educadores, já que a educação ambiental é obrigatória em todos os níveis de ensino e os espaços não escolares são importantes para diversificar o trabalho dos educadores no âmbito escolar, complementando os conteúdos abordados e proporcionando vivências e experiências práticas. Nesse trabalho direto com as crianças e jovens existe uma expectativa por parte das equipes das unidades de conservação de que eles discutam as informações aprendidas na visita à unidade com seus familiares, envolvendo indiretamente o público adulto. Porém, as/os entrevistadas/os apresentaram como uma demanda de pesquisa justamente entender quais são as consequências do trabalho educativo realizado na unidade, já que muitas vezes esse tipo de retorno não é obtido facilmente. Nesse sentido, as atividades contínuas, como os clubinhos, onde as crianças frequentam um espaço de formação em horário oposto ao de estudo semanalmente, foram indicadas em uma das entrevistas como uma alternativa que possibilita maior acompanhamento desses resultados.

Embora seja evidente a ênfase ao público escolar, várias atividades desenvolvidas pelas unidades visitadas envolvem ou poderiam envolver o público adulto (Quadro 3). Muitas vezes, esse público não é priorizado em ações educativas, sob o pressuposto de que as pessoas adultas são incapazes de aprender ou mudar. É comum ouvir, entre educadoras/es e a população em geral, que as crianças são responsáveis em mudar o futuro do planeta (Carvalho, 2001; Guimarães, 2004). Ao contrário, concordamos com a ideia defendida por Freire (2005) e pelas tendências críticas da educação ambiental (Carvalho, 2001; Guimarães, 2004; Oliveira, 2008) de que todas as pessoas sempre podem aprender umas com as outras por meio do diálogo e, assim, transformar a realidade em que vivem. A partir dessa perspectiva, observamos a importância de envolver as pessoas adultas em ações de educação ambiental voltadas para a conservação da biodiversidade, já que estas são as principais tomadoras de decisão nesse contexto.

Nesse sentido, as visitas espontâneas da população local às unidades em busca de lazer, aos finais de semana, representam um potencial para a aproximação deste público. Algumas unidades estudadas possuem uma estrutura específica para lazer como campo de futebol, quiosque para piquenique, como é o caso da Estação Experimental de Tupi; pista de saúde com equipamentos de ginástica, como na Estação Experimental de Itirapina, e trilha interpretativa, como é o caso do Parque Estadual de Vassununga. A recepção dessas pessoas pode ser acompanhada por monitoras/es ou a visita pode ser autoguiada. Assim, diferentemente das unidades do litoral, que atraem turistas de outras regiões do Brasil e do mundo, as unidades do interior paulista possuem atrativos mais direcionados para a população local e, nesse sentido, as estratégias de lazer são muito valiosas tanto para o público infanto-juvenil como para as pessoas adultas (Oliveira e Oliveira, 2012).

Os eventos realizados em datas comemorativas também atraem ou podem atrair a comunidade local, assim como o oferecimento de cursos e oficinas sobre temas de interesse dessas pessoas. Em alguns casos, esse público também é atendido sob demanda, ou seja, algum grupo procura a unidade para trabalhar com alguma necessidade específica. Por exemplo, o fornecimento de mudas atrai produtores rurais que buscam adequar suas propriedades à legislação ambiental. Considerando a conservação da onça parda na região, esse é um público muito importante e ainda pouco envolvido em ações educativas junto às unidades. $\mathrm{O}$ mapeamento das propriedades rurais no entorno das unidades de conservação pode fornecer informações importantes para o futuro planejamento de ações de educação ambiental voltadas para esse público. 
A escolha dos temas a serem abordados nas ações educativas pode ser influenciada por programas institucionais, mas é também realizada pela equipe responsável pela educação ambiental na unidade, e ainda pode envolver a opinião do próprio público. Nessa linha, muitas unidades escolhem temas que refletem os problemas ambientais locais. Nas ações continuadas, a possibilidade das/os participantes opinarem em relação aos temas a serem abordados é maior. Assim como nos trabalhos sob demanda, nos quais o público já procura a unidade com alguma necessidade específica e a unidade busca atendê-la.

Embora o tema da conservação da biodiversidade seja fundamental na educação ambiental das unidades, não há ações voltadas para a conservação de uma espécie ou a um problema ambiental específico. Nenhuma unidade desenvolve ações direcionadas à conservação da onça parda, embora todas tenham algum tipo de registro da presença desta espécie em sua área ou entorno. $\mathrm{Na}$ unidade de Porto Ferreira, há um exemplar de onça parda taxidermizada no centro de visitantes, que pode ser um elemento interessante em ações futuras a serem elaboradas para a conservação da espécie. Outras unidades, como a de Vassununga, também possuem animais taxidermizados em exposição. Em relação ao problema de atropelamento de animais nas rodovias que circundam as unidades, embora o assunto seja apresentado em algumas atividades, há possibilidades de ampliar a abordagem desta problemática.

Por outro lado, a recuperação de áreas degradadas, a produção de mudas e o manejo sustentável são temas que atraem a comunidade do entorno, pessoas da comunidade rural e o público adulto. Esse potencial é ainda maior nas unidades de uso sustentável, onde a vocação do espaço já é voltada para esse fim. Esse resultado é de extrema importância, pois as onças não estão restritas aos limites da unidade de conservação (Miotto et al., 2011; 2012) e o interesse de recuperação das áreas naturais do entorno é fundamental para melhorar a qualidade ambiental da paisagem. Desse modo, destacamos esse tema como um dos que possui maior relevância para a educação ambiental para a conservação da onça parda no nordeste paulista, já que é atrativo para o público adulto e essencial para a melhoria de habitats para a espécie.

\section{CONCLUSÕES}

Com este trabalho pudemos traçar um panorama das potencialidades e limitações das unidades de conservação do nordeste paulista para a realização de ações de educação ambiental voltadas à conservação da biodiversidade e, especialmente, à onça parda (Puma concolor). Embora não tenhamos encontrado programas voltados diretamente à conservação dessas ou de outras espécies, o tema da biodiversidade é recorrente em todas as unidades visitadas. Além disso, identificamos diversas ações que já ocorrem ou que poderiam ser realizadas voltadas ao envolvimento da comunidade do entorno nos trabalhos educativos, especialmente das pessoas adultas. Nesse sentido, alguns projetos voltados à resolução de problemas locais, como os atropelamentos estavam sendo idealizados na época da coleta de dados e, atualmente, estão sendo desenvolvidos. Alguns se relacionam direta ou indiretamente à conservação da onça parda, como a diminuição dos atropelamentos de animais nas rodovias e da perda de habitats, além de um projeto que pretendia envolver a comunidade em ações educativas a partir do aparecimento de uma onça parda na zona urbana do município (Andreolli, 2013), fato que tem ocorrido em várias cidades do Estado.

Destacamos, ainda, que as unidades podem ser espaços privilegiados para a integração dos conhecimentos científicos às ações educativas. Nesses locais, muitas pesquisas sobre biodiversidade e conservação são realizadas. Esses conhecimentos científicos são contextualizados, já que são gerados a partir da realidade local. Ao mesmo tempo, há um grande potencial educativo nas unidades, considerando as possibilidades de contato direto com essa realidade, incluindo os ambientes naturais onde ocorrem as mais variadas relações ecológicas e a interação com os seres humanos. Dessa maneira, uma maior aproximação entre essas duas atividades - a educação ambiental e a pesquisa - realizadas nas unidades pode ajudar a definir estratégias e construir propostas de programas e ações educativas para a conservação da biodiversidade local. 
VALENTI, M.W. et al. Educação ambiental em unidades de conservação do nordeste paulista

\section{AGRADECIMENTOS}

À Adriana Neves (Fundação Florestal) e à Marlene Tabanez (Instituto Florestal), pelo rápido retorno com informações sobre as unidades de conservação e a todas as pessoas que nos receberam tão acolhedoramente nas unidades que visitamos. Agradecemos ao CNPq e à FAPESP, pelo financiamento da Rede Predadores de Topo de Cadeia - SISBIOTA; à CAPES, ao CNPq e à Fapesp pelas bolsas de estudos da primeira, segunda e terceira autoras, respectivamente.

\section{REFERÊNCIAS BILIOGRÁFICAS}

ANDREOLLI, F. C. Análise do significado das Estações Ecológica e Experimental de Itirapina (SP) e sua relação com a comunidade da zona urbana do entorno para subsidiar ações de educação ambiental. 2013. 45 f. Monografia (Graduação em Engenharia Ambiental) - Escola de Engenharia de São Carlos, Universidade de São Paulo, São Carlos.

BATALHA, M.A.; MANTOVANI, W. Reproductive phenological patterns of cerrado plant species at the Pé-de-Gigante Reserve (Santa Rita do Passa Quatro, SP, Brazil): a comparison between the herbaceous and woody floras. Brazilian Journal of Biology, v. 6, p. 129-145, 2000.

BENAYAS, J.; BLANCO, R.; GUTIÉRREZ, J. Evaluación de la calidad de las visitas guiadas a espacios naturales protegidos. Tópicos em Educación Ambiental, v. 2, n. 5, p. 69-78, 2000.

BIZERRIL, M.X.A.; SOARES, C.C.; SANTOS, J.P. Linking community communication to conservation of the maned wolf in central Brazil. Environmental Education Research, v. 17, n. 6, p. 815-827, 2011.

BRASIL. Lei 9.985, de 18 de julho de 2000. Regulamenta o art. $225 \S 1^{\circ}$, incisos I, II, III e VII da Constituição Federal. Institui o Sistema Nacional de Unidades de Conservação da Natureza SNUC e dá outras providências. Disponível em: $<$ http://www.planalto.gov.br/ccivil_03/leis/19985.htm>. Acesso em em: 5 mar. 2014.
BRASIL. Ministério do Meio Ambiente. Educação ambiental: contribuição do Programa Nacional de Educação Ambiental para a Política Nacional de Biodiversidade. Brasília, DF, 2002. 21 p.

BRASIL. Ministério do Meio Ambiente. Diretoria de Educação Ambiental - DEA; Ministério da Educação. Coordenação Geral de Educação Ambiental CGEA. Programa Nacional de Educação Ambiental. Brasília, DF: MMA, 2005. 102 p.

Ministério do Meio Ambiente. Departamento de Educação Ambietanl - DEA/SAIC. Estratégia nacional de comunicação e educação ambiental no SNUC. Brasília, DF: MMA, 2010. 14 p.

CARVALHO, C.A.R.; LEAL FILHO, W.; HALE, W.H.G. An analysis of the problems of developing environmental education in Brazilian Federal protected areas. The Environmentalist, n. 18, p. 223-229, 1998.

CARVALHO, I.C.M. Em direção ao mundo da vida: interdisciplinaridade e educação ambiental. Brasília: Instituto de Pesquisas Ecológicas - IPÊ, 1998. $102 \mathrm{p}$.

. Qual educação ambiental? Elementos para um debate sobre educação ambiental popular e extensão rural. Agroecologia e Desenvolvimento Sustentável, v. 2, n. 2, p. 43-51, 2001.

DENZIN, N.K.; LINCOLN, Y.S. Introdução: a disciplina e a prática da pesquisa qualitativa. In: DENZIN, N. K.; LINCOLN, Y. S. (Org.). $O$ planejamento da pesquisa qualitativa: teorias e abordagens. 2. ed. Porto Alegre: Artmed, 2006. p. $15-42$.

FREIRE, P. Pedagogia do oprimido. Rio de Janeiro: Paz e Terra, 2005. 213 p.

GÓMEZ, J. et al. Metodología comunicativa crítica. Barcelona: El Roure, 2006. 149 p.

GUIMARÃES, M. Educação ambiental e gestão para a sustentabilidade. In: SANTOS, J.E.; SATO, M. A contribuição da educação ambiental à esperança de Pandora. São Carlos: Rima, 2001. p. 183-195. 
VALENTI, M.W. et al. Educação ambiental em unidades de conservação do nordeste paulista

GUIMARÃES, M. Educação ambiental crítica. In: LAYRARGUES, P.P. Identidades da educação ambiental brasileira. Brasília, DF: MMA, 2004. p. 25-34.

HAMÚ, D.; AUCHINCLOSS, E.; GOLDSTEIN, W. Recommendations on the role and impact of education and communication for protected areas management in Latin America. In: HAMÚ, D.; AUCHINCLOSS, E.; GOLDSTEIN, W. (Org.). Communicating protected areas. Gland: IUCN, 2004. p. 3-8.

INSTITUTO BRASILEIRO DE GEOGRAFIA E ESTATÍSTICA - IBGE. Estimativas das populações residentes, segundo os municípios em 1 de julho de 2009. Instituto Brasileiro de Geografia e Estatística, 2009. Disponível em: $<$ http://www.ibge.gov.br/home/estatistica/populacao/ estimativa2009>. Acesso em: 2 out. 2013.

JOLY, C.A. et al. Biodiversity conservation research, training, and policy in São Paulo. Science, v. 328, p. 1358-1359, 2010.

LOUREIRO, C.F.B. Educação ambiental e gestão participativa na explicitação e resolução de conflitos. Gestão em Ação, v. 7, n. 1, p. 37-50, 2004.

MARIN, A.A.; OLIVEIRA, H.T.; COMAR, V. A educação ambiental num contexto de complexidade do campo teórico da percepção. Interciencia, v. 28, n. 10, p. 616-619, 2003.

MENARIN, C.A. À sombra dos jequitibás: patrimônio ambiental e políticas públicas na criação e implantação do Parque Estadual de Vassununga/SP (1969-2005). 2009. 270 f. Dissertação (Mestrado em História e Sociedade) - Faculdade de Ciências e Letras de Assis, Universidade Estadual Paulista, Assis.

MENDONÇA, R. Conservar e criar: natureza, cultura e complexidade. São Paulo: Senac, 2005. $256 \mathrm{p}$.

Educação ambiental vivencial. In: FERRARO-JUNIOR, L.A. Encontros e caminhos: formação de educadoras(es) ambientais e coletivos educadores. Brasília, DF: MMA, 2007. v. 2, p. 117-130.
MENGHINI, F.B.; MOYA-NETO, J.; GUERRA, A.F.S. Interpretação ambiental. In: FERRARO-JUNIOR, L.A. Encontros e caminhos: formação de educadoras(es) ambientais e coletivos educadores. Brasília, DF: MMA, 2007. v. 2, p. 209-218.

MIOTTO, R.A. et al. Genetic diversity and population structure of pumas (Puma concolor) in southeastern Brazil: implications for conservation in a human-dominated landscape. Conservation Genetics, v. 12, p. 1447-1455, 2011.

. et al. Monitoring a Puma (Puma concolor) population in a fragmented landscape in southeast Brazil. Biotropica, v. 44, n. 1, p. 98-104, 2012.

NAVARRO-PEREZ, M.; TIDBALL, K.G. Challenges of biodiversity education: a review of education strategies for biodiversity education. International Electronic Journal of Environmental Education, v. 2, p. 13-30, 2012. Disponível em: $<$ http://www.iejeegreen.com/index. php/iejeegreen/article/viewArticle/42>. Acesso em: 18 jul. 2013.

OLIVEIRA, H.T. Popular education and environmental education in Latin America: converging paths and aspirations. In: GONZÁLEZ-GAUDIANO, E.; PETERS, M.A. Environmental education: identity, politics and citizenship. Rotterdam: Sense Publishers, 2008. p. 219-230.

OLIVEIRA; J.P.F.; SOUZA; S.A.; RIGON, S. Satisfação dos visitantes do Parque Estadual de Porto Ferreira, Porto Ferreira - SP. Fórum da Alta Paulista, v. 8, n. 3, p. 90-95, 2012.

OLIVEIRA, L.R.N. (Org.) Unidades de conservação da natureza. São Paulo: SMA, 2009. 104 p.

OLIVEIRA, S.M.; OLIVEIRA, H.T. Educação ambiental e lazer em unidades de conservação: a fotografia como instrumento de ação junto ao público adulto. In: CONGRESSO BRASILEIRO DE ATIVIDADES DE AVENTURA, 7.; CONGRESSO INTERNACIONAL DE ATIVIDADES DE AVENTURA, 1., Rio Claro. Anais... Rio Claro: UNESP, 2012. p. 181-188.

PADUA, S.M. Primate conservation: integrating communities through environmental education programs. American Journal of Primatology, v. 72, p. 450-453, 2010. 
VALENTI, M.W. et al. Educação ambiental em unidades de conservação do nordeste paulista

QUINTAS, J.S. Introdução à gestão ambiental pública. Brasília, DF: IBAMA, 2002. 128 p.

RODRIGUES, A.S.L. Are global conservation efforts successful? Science, v. 313, p. 1051-1052, 2007.

RODRIGUES, R.R.; BONONI, V.L.R. (Org.). Diretrizes para a conservação e restauração da biodiversidade no estado de São Paulo. São Paulo: Instituto de Botânica: Fundação de Amparo à Pesquisa do Estado de São Paulo - FAPESP: Programa BIOTA/FAPESP, 2008. 248 p.

SAMMARCO, Y.M. Educación ambiental y paisaje en los espacios naturales protegidos de Brasil: contribuiciones a la construcción del documento Encea (Estrategias Nacionales de comunicación y EA para el SNUC). In: MEIRA-CARTEA, P.A. et al. Educación ambiental: investigando sobre la práctica. Barcelona: Organismo Autónomo Parques Nacionales, 2009. p. 202-225.

SANTOS, E.G.; RAMOS, V.S.; CARDOSO, M.M. O programa de uso público da Floresta Estadual de Assis: lazer, educação ambiental e recreação para a sociedade. In: SEMINÁRIO DE INICIAÇÃO CIENTÍFICA DO INSTITUTO FLORESTAL, 4., 2010. Anais... São Paulo: Instituto Florestal, 2010. (IF Sér. Reg., n. 42, 2010). Disponível em: $<$ http://iflorestal.sp.gov.br/publicacoes-if/if-serieregistros/sumario_n42>. Acesso em: 5 mar. 2014.

SANTOS, J.E. et al. Environmental education praxis toward a natural conservation area. Revista Brasileira de Biologia, v. 60, n. 3, p. 361-372, 2000.

SILVA, F.D. Histórico, classificação e análise de centros de educação ambiental no Brasil. 2004. 194 f. Dissertação (Mestrado em Recursos Florestais) - Escola Superior de Agricultura "Luiz de Queiroz”, Universidade de São Paulo, Piracicaba.

TABANEZ, M. et al. Plano de manejo do Parque Estadual de Porto Ferreira. São Paulo: Instituto Florestal, 2003. 20 p. Disponível em: $<$ http://iflorestal.sp.gov.br/files/2013/03/Plano_ de_Manejo_PE_Porto_Ferreira.pdf $>$. Acesso em: 5 mar. 2014.
TALAMONI, S.A.; MOTTA JUNIOR, J.C.; DIAS, M.M. Fauna de mamíferos da Estação Ecológica de Jataí e da Estação Experimental de Luiz Antônio. In: SANTOS, J.E.; PIRES, J.S.R. (Ed.). Estudos integrados em ecossistemas, Estação Ecológica de Jataí. São Carlos: RiMa, 2000. v. 1.

TOLEDO, R.F.; PELICIONI, M.C.F. A educação ambiental nos Parques Estaduais paulistas no âmbito das recomendações de Tbilisi. Práxis Educativa, v. 1, n. 2, p. 57-64, 2006.

VALENTI, M.W. Educação ambiental e biodiversidade em unidades de conservação: mapeando tendências. 2010. 97 f. Dissertação (Mestrado em Ecologia e Recursos Naturais) - Centro de Ciências Biológicas e Saúde, Universidade Federal de São Carlos, São Carlos.

ZANCHETTA, D. et al. Plano de manejo integrado das unidades de Itirapina. São Paulo: Instituto Florestal, 2006. 247 p. 